Brit. J. vener. Dis. (1956), 32, 7.

\title{
KERATODERMIA BLENNORRHAGICA*
}

\author{
BY \\ J. MALCOLM CAMERON \\ Department of Pathology, Southern General Hospital, Glasgow. Formerly of Belvidere Infectious \\ Diseases Hospital, Glasgow
}

Since the lesion was described in 1893 by Vidal, the aetiology and treatment of keratodermia blennorrhagica have always presented difficulty. It is the most frequently encountered and distinctive skin lesion associated with gonococcal and non-gonococcal urethritis. The lesions occur in crops as discrete vesicles quickly increasing in size and becoming pustular ; the diameter of the pustules varying from 5 to $8 \mathrm{~mm}$. Later the lesions become covered with thick horny crusts, thus resembling mountain ranges on a relief map. Local signs and symptoms of an acute inflammatory reaction do not occur, but there is normally a mild pyrexia at the onset of the skin lesion with no exacerbation of the triad. Among 39 cases of Reiter's syndrome seen at Belvidere Hospital between 1949 and 1954, only two cases exhibited keratodermia blennorrhagica.

\section{Case Histories}

Case 1, a male aged 38, developed "lumbago", a thin, grey, watery, urethral discharge, and increased frequency with dysuria 1 week after sexual exposure; 4 days later he developed a mild bilateral conjunctivitis and a tender effusion into his right knee with limitation of movement. Within 24 hrs his right elbow was similarly affected.

On examination, apart from confirming the above, he had a mild pyrexia, aphthous ulcers in his mouth, and balanitis circinata on his penis. Laboratory examination of urethral and prostatic smears revealed no abnormality and the Wassermann reaction and gonococcal complement-fixation test were negative. His erythrocyte sedimentation rate was raised $50 / 85 \mathrm{~mm}$. $/ \mathrm{hr}$ (Westergren).

About 1 month after the onset of the symptoms, a hyperkeratotic skin lesion was seen on both feet for the first time. Biopsy was consistent with the diagnosis of keratodermia blennorrhagica. Cultures of the lesion and from prostatic secretions were negative for pathogenic bacteria and pleuropneumonia-like organisms. He received full courses of sulphonamides, penicillin, and aureomycin. It was only after a second course of aureomycin that improvement was noticed, but the skin lesions healed spontaneously after 16 days.

Case 2, a male aged 39, developed urethral discharge and balanitis with no upset in micturition 3 days after

* Received for publication December 12, 1955. sexual exposure. On the following day his left ankle became red and swollen with limitation of movement, followed 2 days later by the skin lesion on the soles of his feet (Fig. 1, overleaf).

On examination, it was noted that his right knee was swollen with only $70^{\circ}$ of flexion and that he was unable to move his left shoulder and right hip. He had at this time a mild transient bilateral conjunctivitis with an initial mild pyrexia. He was given rest in bed with complete immobilization of the affected joints, which showed no radiographical abnormality. His electrocardiograph was within normal limits and his Wassermann reaction and gonococcal complement-fixation test were negative. His erythrocyte sedimentation rate was $80 / 120 \mathrm{~mm}$. $/$ hr (Westergren); blood urea, $61 \mathrm{mg}$. pər $100 \mathrm{ml}$; t total serum protein, $7.0 \mathrm{gm}$. per $100 \mathrm{ml}$. (albumin 3.4, globulin 3.6).

Biopsy of the skin lesion showed changes consistent with the diagnosis of keratodermia blennorrhagica and culture of the pus from the lesions yielded a coagulasepositive Staphylococcus aureus in pure growth, as described by Twiss and Douglas (1946), but a chorioallantoic egg culture was negative. Organisms morphologically identical with pleuropneumonia-like organisms were seen on urethral smears but attempted cultivation was unsuccessful. Courses of penicillin, sulphonamide, Anthisan, aureomycin, chloramphenicol, ACTH, and butazolidin were administered but the condition seemed to run its own course with ultimate remission of symptoms. The skin lesions, however, were treated with local aureomycin cream with favourable results within 7 days (Fig. 2, overleaf).

\section{Histopathology}

An acute inflammatory infiltrate in the upper corium and the formation of either vesicles (Keim, 1924 ; Lever and Crawford, 1944) or pustules (Carr and Friedman, 1944) in upper epidermis, into which the vesicles transform rapidly, are the first histological changes (Fig. 3). Shortly after the formation of the pustules the rete pegs became elongated and the horny layer parakeratotic; at this stage it is almost indistinguishable from the histological picture of pustular psoriasis or acrodermatitis continua (Lever, 1949). The clinical "mountain relief" appearance of the lesions is due to the greatly thickened horny layer, sometimes several millimetres 


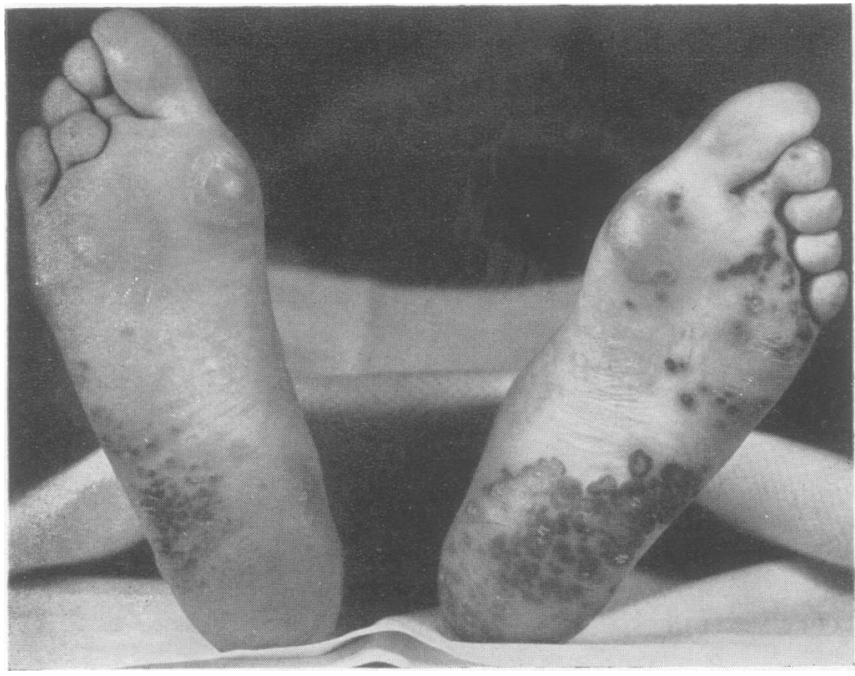

FIG. 1.-Case 2, showing skin lesion before treatment.

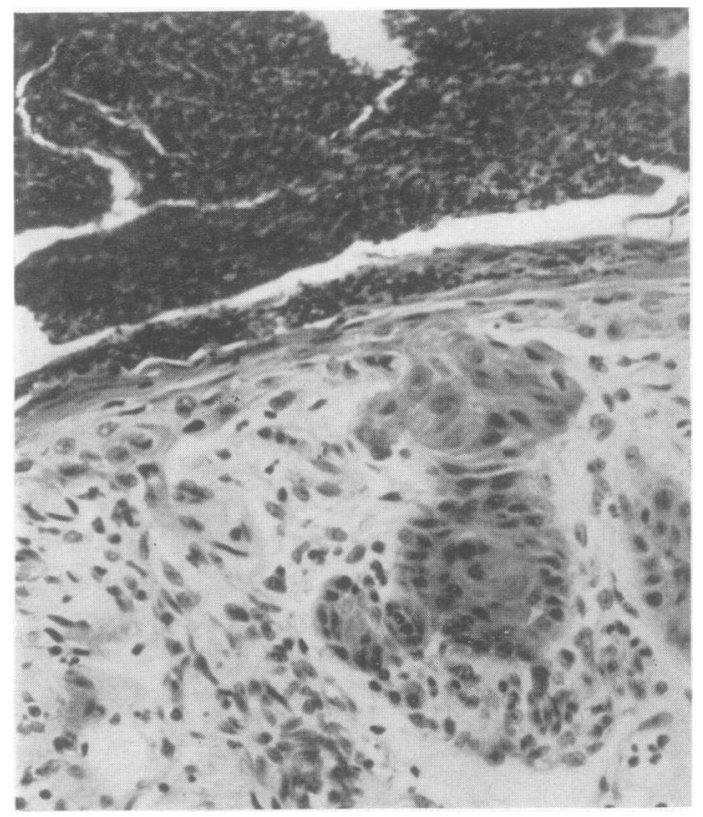

FIG. 3.-Photomicrograph showing thick parakeratotic layer with polymorphonuclear infiltration of the sub-epithelial tissue $(H$. and $\mathrm{E} . \times 200$ ).

in thickness. This degree of thickening is not seen, however, in pustular psoriasis or acrodermatitis continua and is typical of keratodermia blennorrhagica. Herold and Smith (1941) believe that in old lesions no pustulation remains and the horny layer shows only a few areas of parakeratosis and consists mainly of fully keratinized cells.

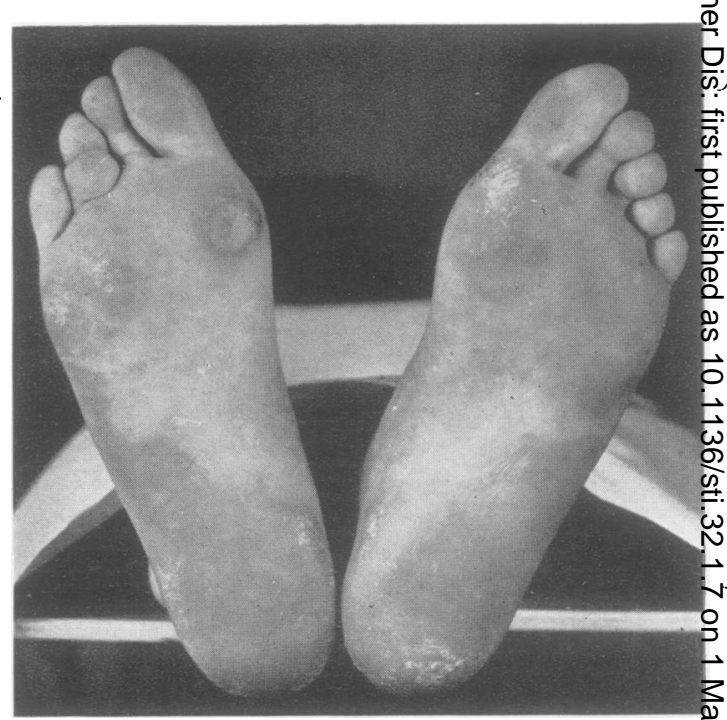

Fig. 2.-Case 2, showing skin lesion after completion of treatment

\section{Summary}

(1) Two cases are reported of Reiter's syndrome exhibiting keratodermia blennorrhagica as an associated skin lesion. Neither case had a previous history of gonococcal infection.

(2) The skin lesions were seen only on the soles of the feet ; balanitis circinata was noted in both patients and aphthous ulcers were seen in the mouth of one.

(3) Culture of the pus from the skin lesion of one case yielded a coagulase-positive Staphylococcus aureus.

(4) Treatment with aureomycin appeared to be beneficial.

I wish to thank Dr. J. G. McGregor-Robertson, former Senior Consultant Venereologist, Western Regional Hospital Board, for permission to publish these cases and Mr. A. H. Harkness, F.R.C.S., for advice and criticism.

\section{REFERENCES}

Carr, J. L., and Friedman, M. (1944). Amer. J. Path., 20, 709. Harkness, A. H. (1950). "Non-gonococcal Urethritis", p. 131. Livingstone, Edinburgh.

Herold, W. C., and Smith, D. C. (1941). Arch. Derm. Syph. (Chicago), 44, 398.

Keim, H. L. (1924). Ibid., 9, 423.

Lever, W. F. (1949). "Histopathology of the Skin", p.137. Lippincott, Philadelphia and London.

-_, and Crawford, G. M. (1944). Arch. Derm. Syph. (Chicago), 49, 389.

Twiss, J. R., and Douglas, A. H. R. (1946). Ann. intern. Med., 24, 1043. Vidal, E. (1893). Ann. Derm. Syph., Paris, Third Ser., 4, 3. Quoted by Harkness, A. H. (1950). 